\title{
Miniaturized Digestion and Extraction of Surface Proteins from Candida albicans following Treatment with Histatin 5 for Mass Spectrometry Analysis
}

\author{
Shirley Fan, ${ }^{1}$ Eduardo B. Moffa, ${ }^{2,3}$ Yizhi Xiao, ${ }^{2,3}$ \\ Walter L. Siqueira, ${ }^{2,3}$ and Ken K.-C. Yeung ${ }^{1,2}$ \\ ${ }^{1}$ Department of Chemistry, Faculty of Science, University of Western Ontario, London, ON, Canada N6A 5B7 \\ ${ }^{2}$ Department of Biochemistry, Schulich School of Medicine and Dentistry, University of Western Ontario, \\ London, ON, Canada N6A 5C1 \\ ${ }^{3}$ Schulich Dentistry, Schulich School of Medicine and Dentistry, University of Western Ontario, \\ London, ON, Canada N6A 5C1
}

Correspondence should be addressed to Ken K.-C. Yeung; kyeung@uwo.ca

Received 22 June 2016; Revised 25 October 2016; Accepted 31 October 2016

Academic Editor: Christian Huck

Copyright (C) 2016 Shirley Fan et al. This is an open access article distributed under the Creative Commons Attribution License, which permits unrestricted use, distribution, and reproduction in any medium, provided the original work is properly cited.

\begin{abstract}
A common approach to isolate surface proteins from fungal and bacterial cells is to perform a proteolytic cleavage of proteins on the surface of intact cells suspended in solution. This paper describes miniaturization of this technique, in which cells are adhered on glass surfaces, and all sample treatments are conducted at $\mu \mathrm{L}$ volumes. Specifically, Candida albicans cells were attached onto HSAcoated glass slides. By depositing the appropriate reagent solutions on the adhered cells, we successfully performed cell washing, treatment with antifugal peptide, Histatin 5 , and a proteolysis on intact cells with trypsin. The resulting peptides were subsequently analysed by mass spectrometry. In general, the data obtained was similar to that collected with suspended cells in much larger sample volumes. However, our miniaturized workflow offers the benefit of greatly reducing the consumption of cells and reagents.
\end{abstract}

\section{Introduction}

Candida albicans is a very common fungus found within the genitourinary and gastrointestinal tracts, as well as on the surface of skins [1]. It exists within humans in a commensal relationship, where it benefits without causing damage [2]. However, individuals with compromised immune systems can develop the infection known as candidiasis $[2,3]$. The most commonly used method to treat infections is to administer antifungal drugs orally or systematically into the circulatory system $[2,4]$. Despite these mechanisms, $C$. albicans has developed resistance towards them [4], and thus, the discoveries of new therapeutic approaches are needed.

For infections to begin, adhesion to oral surfaces of protein films is the initial step $[5,6]$. From these proteins, salivary proteins such as histatins, statherins, and acidic proline-rich ones have exhibited antifungal properties [7, 8]. The family known as histatins (HTN), comprised of HTN1,
HTN3, and HTN5, have been of increasing interest due to its clear ability to control and kill C. albicans $[5,7,9,10]$. Studies targeting the effects of HTN5 on cellular respiration at the mitochondrial level have been performed; however, the exact mechanism remains unknown $[9,11,12]$. Mass spectrometry(MS-) based proteomics is therefore the next logical choice of method in studying C. albicans and its influence by HTN5.

MS is becoming an increasingly popular tool in studying microorganisms. Common applications include protein profiling for taxonomy classification, as well as clinical differentiation between pathogenic and nonpathogenic species [1317]. The degree of classification achieved has been reported down to the genus, species, and strain levels [18]. Mass spectral protein profiling has also been incorporated into studying the response of bacterial cells to drug treatment [19]. Typically, the analysis of the total proteome, of lysed cells, is preferred for a comprehensive, nontargeted characterization. But the use of total cell lysates has its drawbacks. Due to the 
complexity of the proteome and background of lysed cells, sample cleanup and/or fractionation is crucial to obtaining high quality MS data [16]. The identification of a large number of proteins also requires a substantial effort in data analysis. Alternatively, the analysis of intact whole cells offers the benefit of reduced complexity. Anhalt and Fenselau were among the earliest to report the analysis of whole cells for species identification [20]. Through gentle heating in the ion source, phospholipids were vaporized, leading to the production of characteristic mass spectra. Alternatively, species identification through proteins and peptides from whole cell analyses has also been reported [21-23].

When applying MS to study changes in protein levels of C. albicans upon treatment with HTN5, the global approach of studying the total proteome was certainly appropriate. However, our group previously observed a reduction in cell adhesion property upon administration of HTN5 in 90 minutes, suggesting an effect of HTN5 on the surface proteins [24]. Hence, the targeted approach on the surface proteins is logical for studying the influence of HTN5. In 2006, Rodríguez-Ortega et al. reported a protocol called "cell shaving," which allowed them to focus on proteins partially exposed on the outside of cells [25]. This was done by subjecting whole live cells to proteolytic enzymes in a solution. The surface peptides cleaved from intact cells were subsequently isolated for MS analyses. Others have also used a similar approach towards studying surface proteins from other fungal and bacterial species [26, 27]. Despite its effectiveness, the procedure of "cell shaving" is still generally time-consuming. Cells grown in media were harvested and washed, followed by overnight tryptic digestion for 18-20 hours in $\mathrm{mL}$ volume solution. The sample mixture was then centrifuged, and the supernatant was collected for fractionation and/or enrichment prior to injection into the liquid chromatography-mass spectrometer [28-30]. Furthermore, to overcome biological variation and growth variability, the entire procedure was typically repeated for multiple times, thus requiring large quantities of cells and reagents.

In this study, the aim is to refine and miniaturize the existing cell shaving technique, by performing the procedures on adhered $C$. albicans cells rather than suspended cells in solution. We will demonstrate that the attachment of cells on surfaces allows easy introduction and removal of $\mu \mathrm{L}$ volume reagents solutions with a micropipette. Furthermore, treatment with antifungal peptide, HTN5, is readily performed on the adhered cells. We will also demonstrate that the $\mu \mathrm{L}$ sample volume resulting from our miniaturized approach is directly compatible with subsequent MALDI MS and/or LC ESI MS/MS analyses. Importantly, the resulting MS data should be comparable to previous information obtained with the conventional, in solution, approach that required much larger quantities of reagent and cells.

\section{Materials and Methods}

2.1. C. albicans Culturing. The strain of C. albicans used for all experiments was ATCC90028. Stock cultures of cells were grown on plates containing Sabouraud dextrose agar (SDA) medium (Becton Dickson and Company, NJ, USA). The

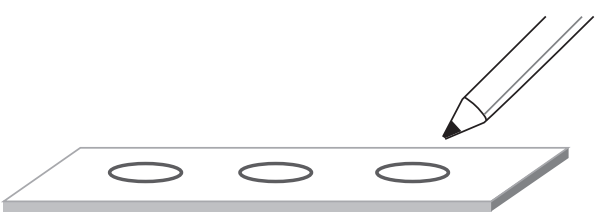

(a)

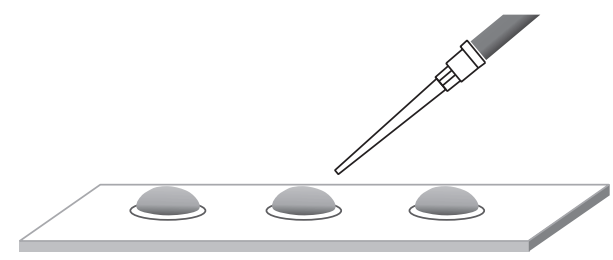

(b)

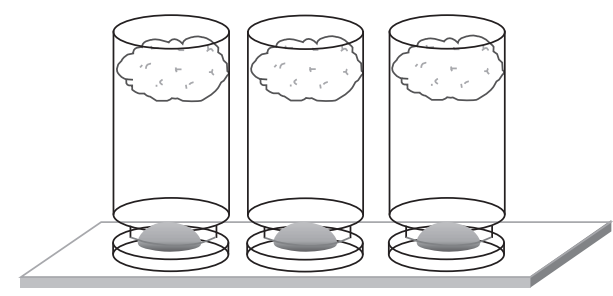

(c)

FIgURE 1: Schematics of the miniaturized procedures of cell adhesion, treatment, and tryptic digestion. Description is presented in Materials and Methods.

inoculated plates were incubated at $37^{\circ} \mathrm{C}$ for 48 hours. A third of a loop of the colonies were transferred into $45 \mathrm{~mL}$ of yeast nitrogen base (YNB), supplemented with $50 \mathrm{mM}$ sucrose (Sigma Aldrich, MO, USA). The mixture was then incubated at $37^{\circ} \mathrm{C}$ for 21 hours under shaking at $200 \mathrm{rpm}$. Following the incubation, the mixture was centrifuged at $6000 \mathrm{rpm}$ for 5 minutes. The pellet was resuspended in phosphate buffered saline solution (PBS, $\mathrm{pH} 7.4$, Sigma Aldrich). The final cell suspension was stored at $4^{\circ} \mathrm{C}$ until use.

\subsection{Adhesion of C. albicans to Glass Slides and Treatment} with HTN5. A Dako delimiting pen, composed of 60-100\% 1bromopropane and 5-10\% dipentene (Cedarlane, Burlington, CA), was used to draw circles with an inner diameter of roughly $6 \mathrm{~mm}$ on standard microscope glass slides (Figure 1(a)). The hydrophobic ink functioned as a barrier to surround a droplet of aqueous sample solution. A total of three circles were made on each glass slide (Figure 1(b)). During an experiment, each sample spot was covered with an inverted glass vial containing a wet cotton, which maintained a high humidity environment and minimized evaporation of the sample droplet (Figure 1(c)). To prepare for cell adhesion, the glass surface within the hydrophobic circles was treated with $25 \mu \mathrm{L}$ of $0.10 \mathrm{mg} / \mathrm{mL}$ human serum albumin (HSA) solution (Sigma Aldrich) for 2 hours at room temperature (RT), based on a protocol previously reported by our group [5]. The HSA-coated surface was then washed three times with water. Next, $25 \mu \mathrm{L}$ of $C$. albicans suspension, at a concentration of $10^{7}$ cells $/ \mathrm{mL}$, was introduced to the HSAcoated slide. The adhesion was carried out under a 90-minute 
incubation at RT. The surface with adhered cells was then rinsed three times with PBS to remove the unattached cells. For the HTN5 treatment, $25 \mu \mathrm{L}$ of HTN5 solution (ChinaPeptides Company, Shanghai, China) at various concentrations was deposited to the cells. When not specified, a HTN5 concentration of $30 \mu \mathrm{g} / \mathrm{mL}$ was used. The HTN5 treatment was done for $90 \mathrm{~min}$ at RT, which was the minimum time to observe a clear effect of HTN5 on C. albicans [24]. The final samples of treated cells on the glass slide were washed three times with water.

2.3. Tryptic Digestions on Solid Support. In a previous report, the trypsin digestion of surface proteins on C. albicans cells, suspended in buffer solution, was performed at a trypsin concentration of $10 \mu \mathrm{g} / \mathrm{mL}$ trypsin for up to $20 \mathrm{~min}$ [28]. The authors also performed propidium iodide staining experiment to confirm that the $C$. albicans cells were not permeabilized by trypsin. In this work, digestions were performed on adhered $C$. albicans cells, with or without HTN5 treatment, on glass surfaces within the hydrophobic circles at RT. It was therefore necessary to reoptimize the digestion time and trypsin concentration. Due to the large number of experiments required to map these two parameters, we decided to first evaluate the digestion using a standard protein, cytochrome $c$ from horse heart (Catalogue number C2506, Sigma Aldrich). For all digestions in this work, tosyl phenylalanyl chloromethyl ketone- (TPCK-) treated trypsin resuspended in $50 \mathrm{mM}$ ammonium bicarbonate (Sigma Aldrich) was used.

To determine the optimal digestion time for cytochrome c, a very high concentration of trypsin was initially used to ensure that it was not a limiting factor. Specifically, $0.36 \mu \mathrm{L}$ of $0.1 \mathrm{mg} / \mathrm{mL}$ cytochrome $\mathrm{c}$ was mixed with $0.36 \mu \mathrm{L}$ of $1.0 \mathrm{mg} / \mathrm{mL}$ trypsin to perform the digestion directly on a MALDI sample target plate, under a range of digestion times from 0.25 to $60 \mathrm{~min}$. After the optimal time was determined based on MALDI MS results, which turned out to be $10 \mathrm{~min}$, the digestion was then performed on adhered C. albicans cells. The trypsin concentration used was reduced to a range comparable to that reported in the literature [28], namely, 0.5 to $2.0 \mu \mathrm{g} / \mathrm{mL}$, and a volume of $3 \mu \mathrm{L}$ was used. The optimal trypsin concentration was determined to be $1.5 \mu \mathrm{g} / \mathrm{mL}$ based on MALDI MS results. Finally, using this trypsin concentration, we reexamined the digestion time study with adhered C. albicans cells. The MALDI MS results confirmed that the optimal digestion time remained at $10 \mathrm{~min}$. Finally, following the digestion step performed on C. albicans cells, the trypsin solution, now with resulting peptides, was recovered using a micropipette for subsequent MALDI MS or LC ESI MS/MS analyses.

2.4. MALDI MS Analysis. The $\alpha$-cyano-4-hydroxycinnamic acid (CHCA) matrix solution was prepared at $5.5 \mathrm{mg} / \mathrm{mL}$ in $6 \mathrm{mM}$ ammonium phosphate monobasic, 50\% acetonitrile, and $0.1 \%$ trifluoroacetic acid (Sigma Aldrich). The recovered peptides, $0.72 \mu \mathrm{L}$ from cytochrome c or $3 \mu \mathrm{L}$ from C. albicans, were mixed in a $1: 1(\mathrm{v} / \mathrm{v})$ ratio with this CHCA matrix solution. All sample-matrix mixtures were spotted at a volume of $0.75 \mu \mathrm{L}$ on a 384 well Opti-TOF $123 \times 83 \mathrm{~mm}$ SS MALDI plate (Sciex, MA, USA). The instrument is equipped with a $349 \mathrm{~nm}$ OptiBeam On-Axis laser with a pulse rate at $400 \mathrm{~Hz}$. Data acquisition and processing were done using TOF-TOF Series Explorer (Sciex) and Data Explorer. The spectra were acquired in Reflectron positive mode from $500-3500 \mathrm{~m} / z$. Peak lists were created using the following parameters: a peak density of 10 per $25 \mathrm{Da}$, minimal signal-to-noise (S/N) of 10 , minimum area of 50 , and a maximum peak per spot of 200. Second fragmentation, MS/MS, was also performed via postsource decay (PSD) using the $1 \mathrm{kV}$ in positive ion acquisition mode.

2.5. Nano-HPLC ESI MS/MS. Prior to injection for LC MS, the peptide sample $(3 \mu \mathrm{L})$ underwent sample cleanup using $\mathrm{C}_{18}$ ZipTip (Millipore, MA, USA). The eluted peptides were then dried and concentrated by the Vacufuge vacuum concentrator (Eppendorf, Germany). This was performed at RT for 10 minutes at $14000 \mathrm{rpm}$. Once dried, the peptides were resuspended in $10 \mu \mathrm{L}$ of $0.1 \%$ formic acid (Sigma Aldrich), with $8 \mu \mathrm{L}$ of this sample injected to LC MS.

Nano-HPLC was carried out on an Thermo Scientific Easy nLC II instrument (Thermo Scientific, CA, USA). The 85-minute gradient composition ranged from 5 to $55 \%$ of solvent B, which was $97.5 \%$ acetonitrile and $0.1 \%$ formic acid (Sigma Aldrich). Solvent A is $0.1 \%$ FA in water. The flow rate used was $200 \mathrm{~nL} / \mathrm{min}$ at a pressure of 280 bar. The volume of sample injected was $8 \mu \mathrm{L}$. ESI was conducted using a voltage of $2.0 \mathrm{kV}$ with an ion transfer capillary temperature of $250.0^{\circ} \mathrm{C}$.

MS analyses were performed on a Thermo Scientific linear trap quadrupole (LTQ) Velos ion mass spectrometer (Thermo Scientific). Positive mode data acquisitions and processing were done using Thermo Xcalibur 2.1.0 SP1.1162 software (Thermo Scientific, USA). The MS scan $\mathrm{m} / z$ range used was $0-2000$. MS/MS was done via collision induced dissociation (CID) using helium (He) as the inert gas.

2.6. Database Searches. All MALDI MS spectra were searched against the Uniprot protein database (SwissProt 2015_02, 547599 entries) on MASCOT provided by Matrix Science (http://www.matrixscience.com/). The search parameters used for C. albicans were (1) trypsin with one missed cleavage, (2) fungi as the taxonomy, (3) a variable modification for the oxidation of methionine, and (4) a mass tolerance of $\pm 70 \mathrm{ppm}$.

All ESI MS/MS spectra were run through the Thermo Proteome Discoverer version 1.3.0.339 software (Thermo Fisher Scientific Inc., USA), using the algorithm known as SEQUEST. The C. albicans database chosen to search results against was the UniProt Knowledgebase, more commonly known as UniProtKB. (UniProt Consortium, http://www .uniprot.org/). The data analysis program SEQUEST was used for protein identification. The search parameters were as follows: (1) enzymatic cleavage by trypsin with up to 2 missed cleavages, (2) signal-to-noise ratio $(\mathrm{S} / \mathrm{N})$ of $1.5,(3)$ precursor mass tolerance of $\pm 2 \mathrm{Da}$, and (4) fragment mass tolerance of $\pm 0.8 \mathrm{Da}$. 


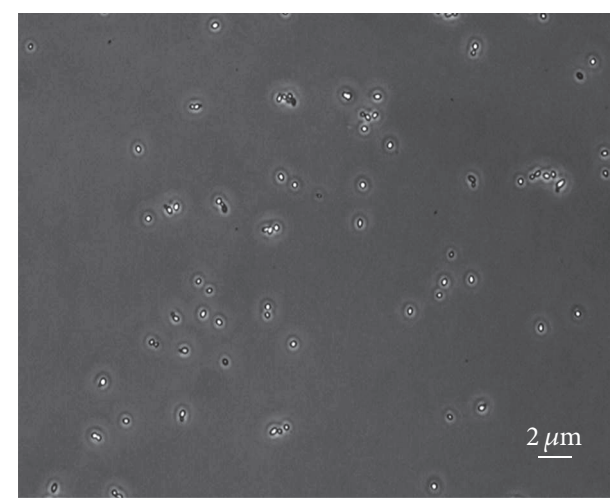

(a) Control

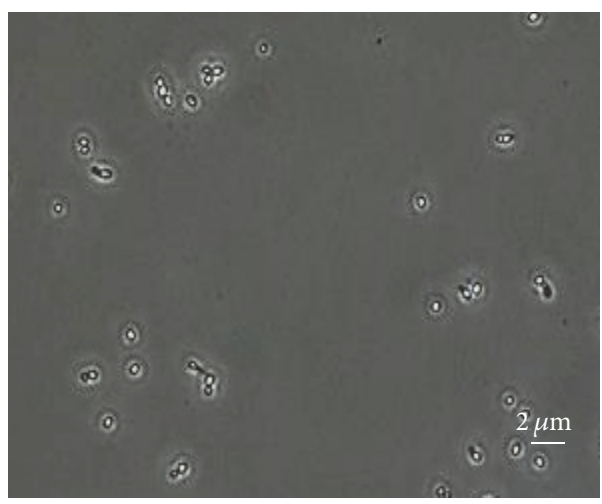

(c) $25 \mu \mathrm{g} / \mathrm{mL}$

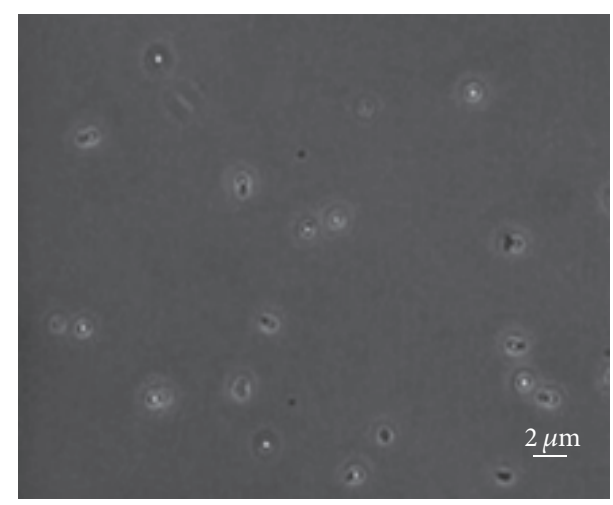

(b) $30 \mu \mathrm{g} / \mathrm{mL}$

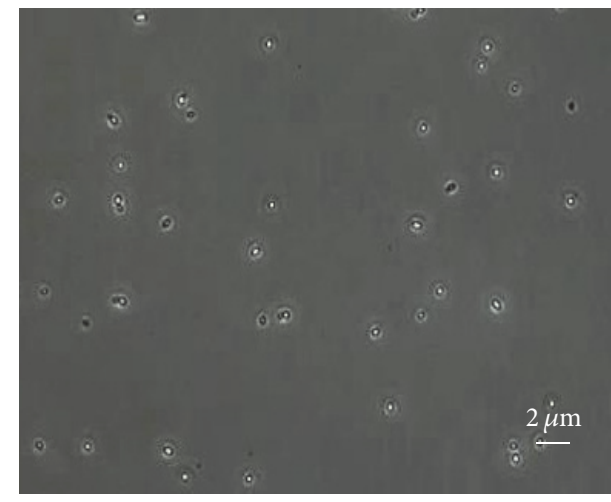

(d) $20 \mu \mathrm{g} / \mathrm{mL}$

Figure 2: Microscope images of C. albicans adhered on slides after a 2-hour treatment with Histatin 5. The concentrations of HTN5 are indicated in (b-d) with units of $\mu \mathrm{g} / \mathrm{mL}$. The average cell counts $(n=4)$ with standard deviations were (a) $110 \pm 8$, (b) $16 \pm 8$, (c) $25 \pm 5$, and (d) $42 \pm 4$.

\section{Results and Discussion}

3.1. C. albicans Cell Adhesion and HTN5 Treatment. Our research team previously studied and reported fungicidal activity of HTN5 on C. albicans [24]. The results indicated that preexposition of HTN5 to oral epithelial cells diminished the adhesion of $C$. albicans to the epithelium. Since the miniaturized assay in this work is performed on adhered cells, it is important to determine an optimal dosage of HTN5 which is sufficient to cause detected changes in protein abundance, but not too high to eradicate and desorb all cells from the glass surface.

To begin, we reproduced the adhesion of C. albicans on HSA-coated glass surfaces as previously reported [5], and then the cells were treated with varying concentrations of HTN5. Given the physiological concentration of HTN5 in the oral cavity, 10-30 $\mu \mathrm{M}$ [31], we performed HTN5 treatments at 20,25 , and $30 \mu \mathrm{g} / \mathrm{mL}$ (Figures 2(b) and 2(c)). A 2-hour treatment time was selected, based on the previous observation that 90 min was sufficient to cause a reduction in C. albicans colonization [24]. Figure 2 shows the typical microscopical views of the adhered cells after HTN5 treatments. The average cell count numbers presented in the caption refer to counts within the microscopical views. As expected, a reduction in cell counts after exposure to HTN5 was evident, and the effect was greater at higher HTN5 concentration.
Given that sufficient cells remained adhered even at the highest concentration studied, $30 \mu \mathrm{g} / \mathrm{mL}$, we chose to use this concentration in subsequent HTN5 treatments to maximize changes in the C. albicans protein levels.

3.2. Tryptic Digestions Performed on Adhered Cells. Prior to performing digestion of $C$. albicans cells adhered on glass surfaces, an optimization of the tryptic digestion conditions was conducted. The first objective was to determine the shortest reaction time require to complete a digestion with an excess quantity of trypsin. We chose to conduct this study on a standard protein, cytochrome c. In contrast to working with cells, the use of a standard protein allows us to easily control the amount of starting materials and provides a set of well-defined tryptic peptide products as the reaction end-point. Triplicate digestions at RT were conducted under the concentrations of $0.05 \mathrm{mg} / \mathrm{mL}$ for cytochrome $\mathrm{c}$ and $0.5 \mathrm{mg} / \mathrm{mL}$ for trypsin, at a total volume of less than $1 \mu \mathrm{L}$. The reaction time durations studied were $0.25,0.5,0.75,1,2,3,4$, $5,10,15,20,25,30$, and 60 minutes. It was observed that the shorter digestion times of 15 seconds to 4 minutes produced considerably low peptide signals (data not shown). The most critical changes in number of peptides and/or peak intensities occurred between 5 and 15 minutes of digestion time. A total of eight tryptic peaks of cytochrome $c$, with up to 1 missed cleavage, were detected ( $m / z$ of: $634.39,1168.62,1260.58$, 
$1296.72,1454.81,1495.70,1598.78$, and 1633.82). The changes in peak intensities of these eight peptides between digestion periods of 5 to 15 minutes are shown in Figure S1 (see Supporting Information in Supplementary Material available online at http://dx.doi.org/10.1155/2016/9812829). Essentially, highest signals were recorded from the digestion time of 10 minutes. Beyond 10 minutes, the digestion appeared to be completed, and the opposing effect of peptide loss due to nonspecific adsorption on surfaces was speculated.

Using the optimal digestion time of 10 minutes for cytochrome c, we subsequently optimized the trypsin concentration for the adhered $C$. albicans cells. The trypsin concentrations used for this experiment were $0.5,0.75,1$, 1.5 , and $2 \mu \mathrm{g} / \mathrm{mL}$. Five replicate digestion experiments were conducted by depositing $3 \mu \mathrm{L}$ of trypsin solution at various concentrations on adhered cells as shown in Figure 1. From the 25 resulting mass spectra, peaks with $\mathrm{S} / \mathrm{N}$ above 10 were extracted for their values of $m / z$ and peak height. Background signals from trypsin and HSA were removed from the list, and averages of peak intensities were taken from replicates. The two lowest concentrations studied, 0.5 and $0.75 \mu \mathrm{g} / \mathrm{mL}$, resulted in noticeably fewer peaks, and so only the results from the higher three concentrations were shown in Table S1 (under Supporting Information). Based on the number of signals observed, our results indicated that $1.5 \mu \mathrm{g} / \mathrm{mL}$ was the optimal. In addition, the peak intensities were also highest at this concentration in most cases.

Once again, the optimal digestion time of $10 \mathrm{~min}$ was previously determined using cytochrome c. In case this optimal value is substrate-specific, we reexamined the effect of digestion time for $C$. albicans at a trypsin concentration of $1.5 \mu \mathrm{g} / \mathrm{mL}$. Four digestion times, 5, 10, 15, and 20 minutes, in replicates of four were studied. The results are presented in Table S2, which confirmed that 10 minutes remained to be optimal in yielding the highest number of signals. Previous work performed the isolation of surface peptides from C. albicans in solution under digestion times from five to twenty minutes [28]. They reported that five minutes was sufficient for the release of easily accessible surface peptides, and as the time was increased, the number of resulting peptides increased as well. Our data generally agreed with their observations. Even though the greatest number of peaks was observed at 10 minutes, the peak intensities of some peaks continued to increase beyond 10 minutes, for example, $m / z$ of $656.0,851.4,1111.5$, and 2447.0. However, we have not yet confirmed which of these signals originated from C. albicans, and thus the comparison should not be based on the intensities of selected peaks. This led us back to the conclusion of 10 minutes being optimal based on the highest number of observed peaks.

Most importantly, the results demonstrated the successful tryptic digestion performed on C. albicans adhered on glass, with as little as $3 \mu \mathrm{L}$ of trypsin solution. Using the established optimal reaction time of $10 \mathrm{~min}$ and trypsin concentration of $1.5 \mu \mathrm{g} / \mathrm{mL}$, digestions were performed finally on C. albicans cells treated with HTN5. The resulting peptides were recovered for analysis by LC ESI MS/MS for identification.
3.3. Analyses of Peptides from C. albicans by Nano-HPLC ESI MS/MS. ESI MS and MS/MS data were generated for samples collected from the tryptic digestion of $C$. albicans cells, with and without HTN5 treatments. The entire study was performed in replicates of six for each of the two groups, and the results were searched against the C. albicans database for protein identification. It is noteworthy that the nature of our miniaturized assay, while reducing the consumption of reagents and cells, also produces a limited quantity of peptides for protein identification. It was estimated that less than $2 \mu \mathrm{g}$ of materials was injected for each LC MS analysis. For this reason, we have taken a less stringent approach in setting our database search parameters, and so we can include results with moderate to high levels of confidence. Furthermore, instead of focusing only on peptides with substantial changes in abundance after exposure to HTN5, we also take the inclusive approach and present the different levels of abundance changes resulting from the treatment. To help readers distinguishing the peptides detected with increased intensities from those with reduced intensities following HTN5 treatment, the results are divided into two tables. Table 1 presents the precursor ions with average intensities that were higher from the HTN5 treated samples compared to the control, whereas Table 2 shows the ions with lower intensities from the treated group compared to the control. The $p$ values resulting from $t$-test are included in the tables to illustrate the significance of the signal intensity changes. Entries with high $p$ values $(>0.1)$ should be treated as statistically indistinguishable. The signal intensities of these ions were highly variable within the replicate measurements, which resulted in large standard deviations and low statistical confidences.

The confidences of protein assignments were also illustrated in the tables as $X_{\text {Corr }}$ values. $X_{\text {Corr }}$ values above 2 are usually indicative of a good correlation. It is noteworthy that some observed precursor ions were matched with multiple theoretical precursor ions; for example, observed $m / z 1297.59$ was matched with theoretical $m / z 1298.54,1297.49,1297.69$, $1297.70,1297.75$, and 1298.67. Readers should take into account the $X_{\text {Corr }}$ scores when interpreting the results, as some of these protein assignments are only putative. Finally, the protein entries were sorted according to their biological functions, but these listed functions were taken straight out of the Uniprot database based on the accession numbers resulting from the search (listed next to the protein names in Tables 1 and 2). Further experimental verifications were not conducted in this work.

In the previous study of peptides resulting from cell shaving of C. albicans in solution [28], the authors reported the detection of proteins with the following functions: metabolism, cell defense and virulence, transport, and protein fate. Likewise, the profiling of C. albicans surface proteins was reported by two other groups in different analytical approaches [29, 32]. Broadly speaking, similar functions were observed in Tables 1 and 2. While these previous reports offered more comprehensive listings of proteins with cell wall functions, our work focused on the changes in surface proteins upon HTN5 treatment. 


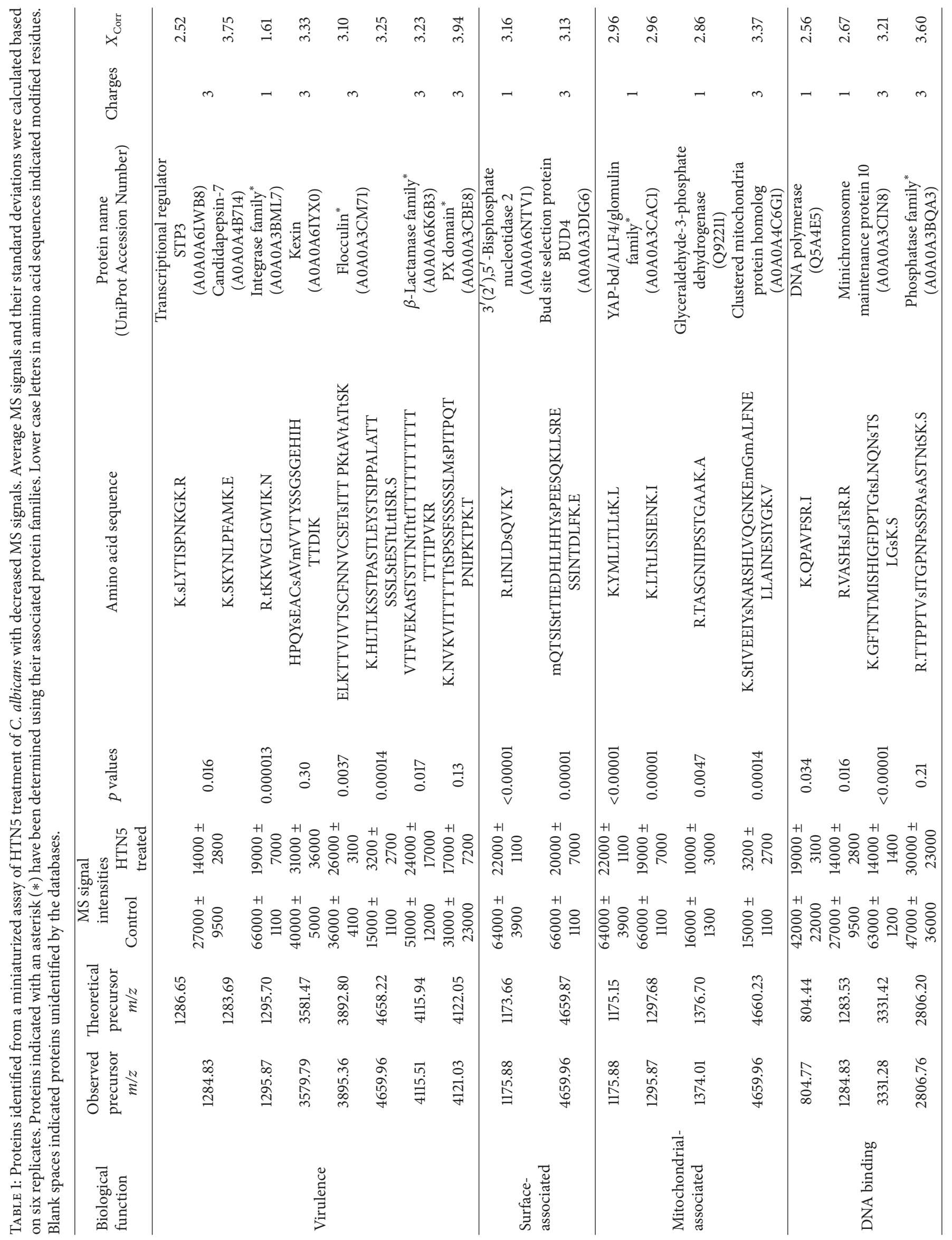




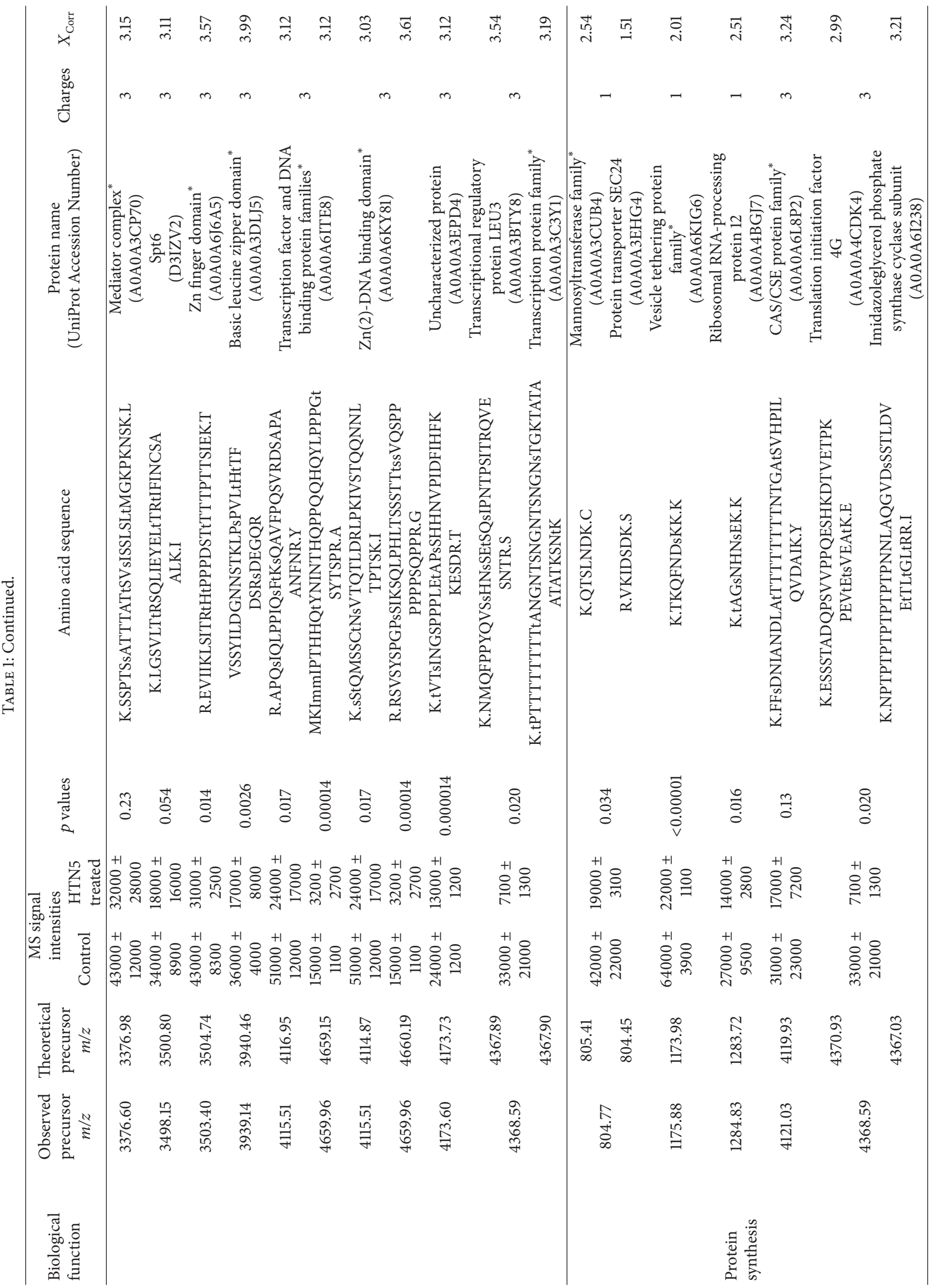




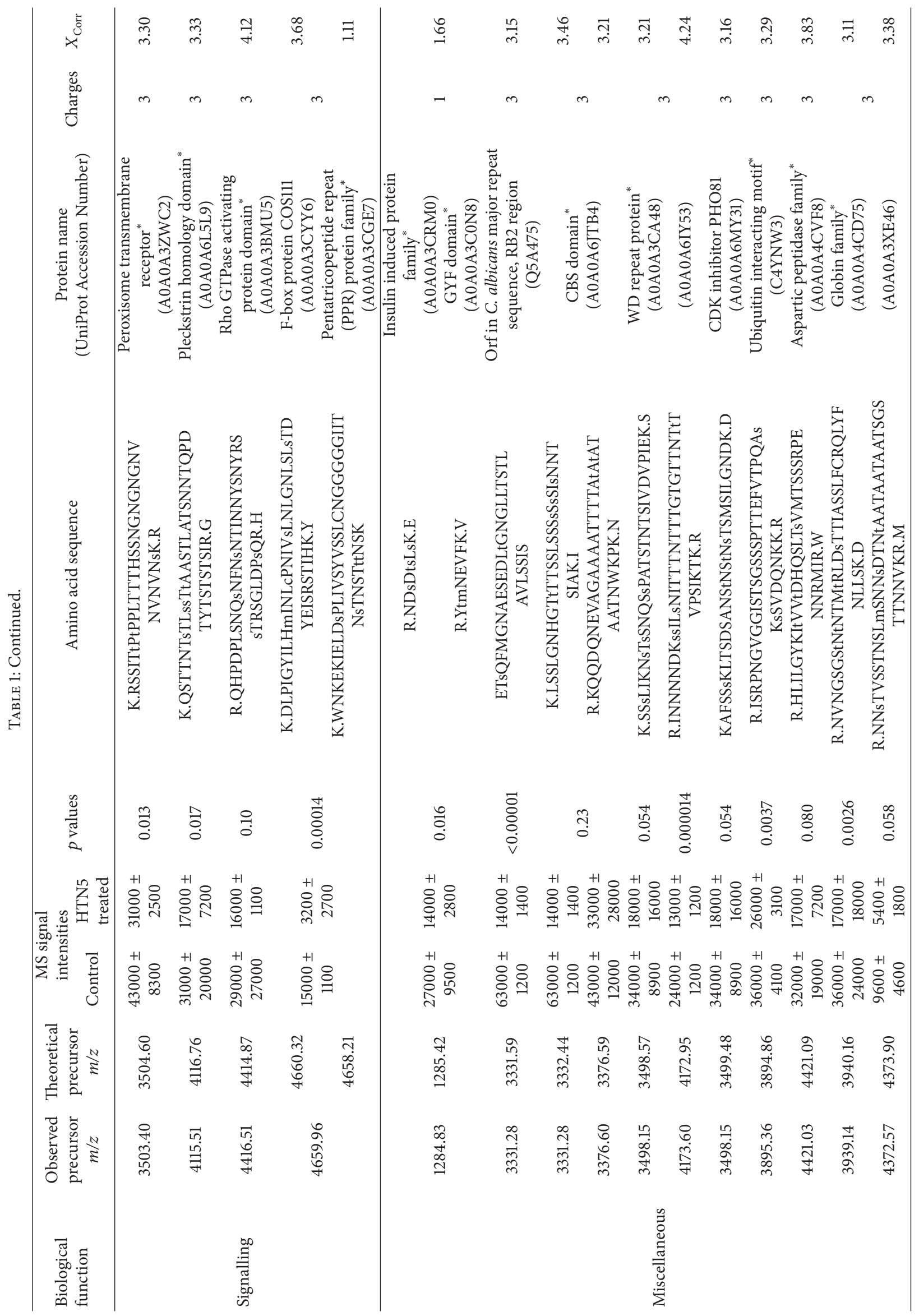




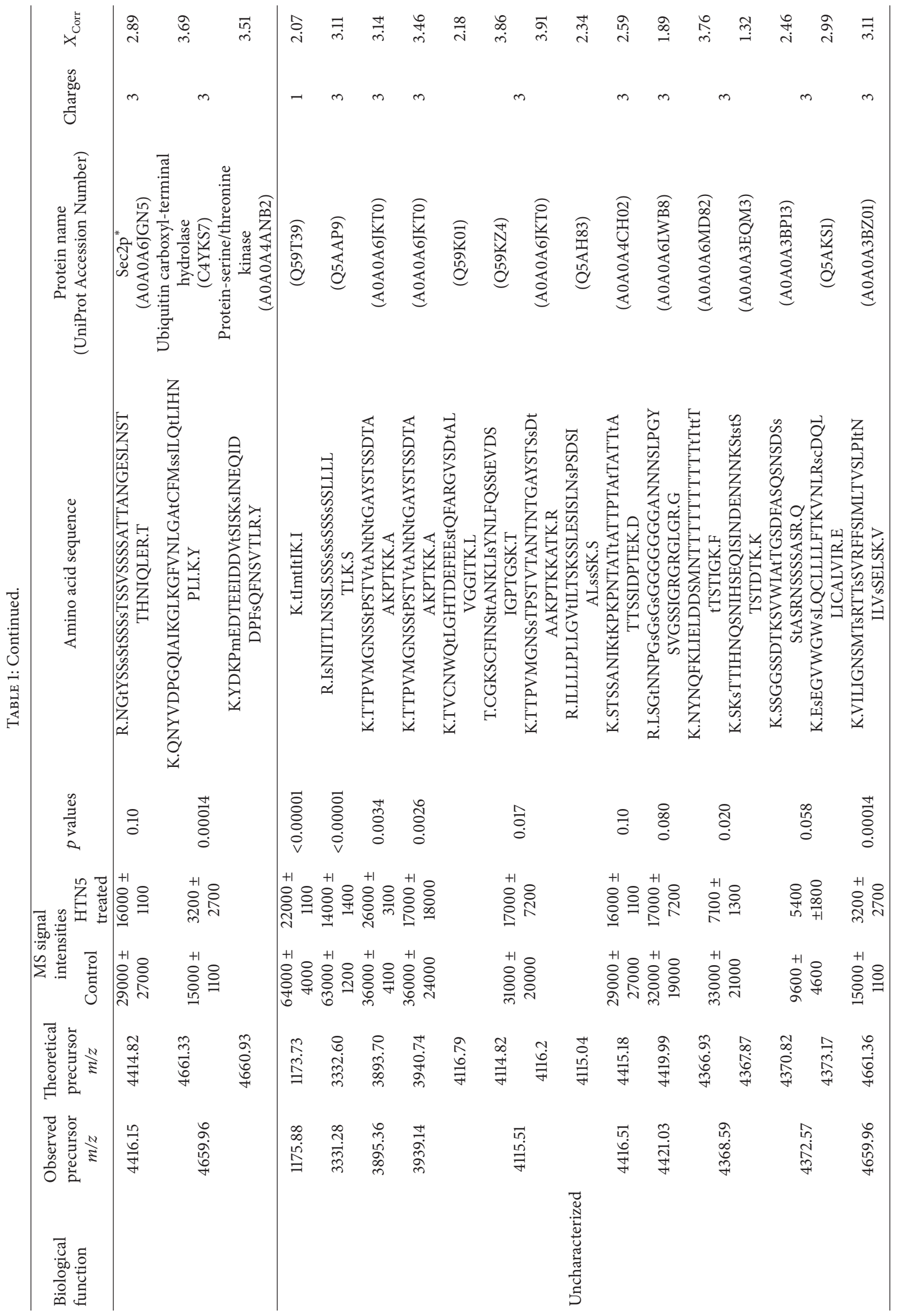


TABLE 2: Proteins identified from a miniaturized assay of HTN5 treatment of C. albicans with increased MS signals. Average MS signals and their standard deviations were calculated based on six replicates. Proteins indicated with an asterisk (*) have been determined using their associated protein families. Lower case letters in amino acid sequences indicated modified residues. Blank spaces indicated proteins unidentified by the databases.

\begin{tabular}{|c|c|c|c|c|c|c|c|c|c|}
\hline \multirow[b]{2}{*}{$\begin{array}{l}\text { Biological } \\
\text { function }\end{array}$} & \multirow{2}{*}{$\begin{array}{c}\text { Observed } \\
\text { precursor } \\
m / z\end{array}$} & \multirow{2}{*}{$\begin{array}{c}\text { Theoretical } \\
\text { precursor } \\
\mathrm{m} / \mathrm{z}\end{array}$} & \multicolumn{2}{|c|}{ Ion counts } & \multirow[b]{2}{*}{$p$ values } & \multirow[b]{2}{*}{ Amino acid sequence } & \multirow[b]{2}{*}{ Protein name } & \multirow[b]{2}{*}{ Charges } & \multirow[b]{2}{*}{$X_{\text {Corr }}$} \\
\hline & & & Before & After & & & & & \\
\hline $\begin{array}{l}\text { Surface- } \\
\text { associated }\end{array}$ & 1297.59 & 1298.54 & $\begin{array}{c}18000 \pm \\
8800\end{array}$ & $\begin{array}{l}51000 \pm \\
5400\end{array}$ & 0.00042 & K.KPsTEDtFSK.Y & $\begin{array}{c}\text { Peroxisomal protein } \\
\text { family }^{*} \\
\text { (A0A0A6JC81) } \\
\end{array}$ & 1 & 1.82 \\
\hline $\begin{array}{l}\text { Mitochondrial- } \\
\text { associated }\end{array}$ & 1297.59 & 1297.49 & $\begin{array}{c}18000 \pm \\
8800\end{array}$ & $\begin{array}{l}51000 \pm \\
5400\end{array}$ & 0.00042 & R.NsIttEsVK.A & $\begin{array}{c}\text { Aldehyde hydrogenase } \\
\text { family* }^{*} \\
\text { (A0A0A3BNV6) }\end{array}$ & 1 & 2.03 \\
\hline \multirow{3}{*}{ DNA binding } & 575.44 & 576.45 & $\begin{array}{l}9700 \pm \\
1000\end{array}$ & $\begin{array}{l}28000 \pm \\
6200\end{array}$ & 0.00055 & K.SLLSR.I & $\begin{array}{l}\text { Telomerase reverse } \\
\text { transcriptase family* } \\
\text { (C4YDL3) }\end{array}$ & 1 & 1.54 \\
\hline & \multirow[b]{2}{*}{1297.59} & 1297.75 & \multirow[b]{2}{*}{$\begin{array}{c}18000 \pm \\
8800\end{array}$} & \multirow[b]{2}{*}{$\begin{array}{l}51000 \pm \\
5400\end{array}$} & \multirow[b]{2}{*}{0.00042} & K.NVIPAtItK.V & $\begin{array}{c}\text { Spt6 } \\
\text { (D3IZV2) }\end{array}$ & & 1.54 \\
\hline & & 1298.67 & & & & K.EFTIGPFKcIK.W & $\begin{array}{c}\text { Transcriptional } \\
\text { regulatory protein } \\
\text { family* }^{*} \\
\text { (A0A0A3CXJ5) }\end{array}$ & 1 & 1.56 \\
\hline \multirow{2}{*}{ Miscellaneous } & 575.44 & 576.31 & $\begin{array}{c}9700 \pm \\
1100\end{array}$ & $\begin{array}{c}28000 \pm \\
6200\end{array}$ & 0.00055 & R.SLNSR.I & $\begin{array}{l}\text { ATPase family* } \\
\text { (A0A0A4CD62) }\end{array}$ & 1 & 3.15 \\
\hline & 1901.71 & 1903.74 & $\begin{array}{c}7800 \pm \\
3900 \\
\end{array}$ & $\begin{array}{c}13000 \pm \\
2300\end{array}$ & 0.025 & K.NKATssSSStsRDTR.W & $\begin{array}{c}\text { Leucine rich repeats* } \\
(\mathrm{C} 4 \mathrm{YMX} 3)\end{array}$ & 2 & 3.19 \\
\hline \multirow{2}{*}{ Uncharacterized } & \multirow{2}{*}{1297.59} & 1297.69 & \multirow{2}{*}{$\begin{array}{c}18000 \pm \\
8800\end{array}$} & \multirow{2}{*}{$\begin{array}{l}51000 \pm \\
5400\end{array}$} & \multirow{2}{*}{0.00042} & R.NNTtVSKGRIK.V & (A0A0A6M207) & & 1.51 \\
\hline & & & & & & & & & 1.60 \\
\hline
\end{tabular}

In another previous study, quantitative LC MS was performed to characterize changes in the mitochondrial proteome of C. albicans upon HTN5 treatments [33]. The authors reported an upregulation of mitochondrial proteins mainly involved in genome maintenance and gene expression and a downregulation for respiratory enzyme complexes. In our work, the MS analysis was performed on samples resulted from the tryptic shaving of adhered intact cells. Given that the two approaches focused on different parts of the proteome, we should not directly compare the proteins identified from these studies. It suffices to conclude that a general decrease in MS signals was observed in our work for many virulence- and surface-associated proteins after HTN5 treatment, as one would expect. Finally, readers should be reminded that the peptide sample quantity produced from our miniaturized technique was substantially lower than that typically used in previous studies, due to the lower amount of starting materials in our work. Nevertheless, one could alleviate this limitation by increasing the density of adhered cells on glass with a cell suspension of higher concentration and/or by increasing the surface area used of each assay, which is defined by the hydrophobic boundary made by the user. An increase in cell number per assay will directly increase the quantity of peptides produced for LC MS analysis and subsequently improve the number of proteins identified and/or the confidence of the identification.

\section{Conclusions}

This paper reported successful miniaturization of the tryptic digestion of surface proteins performed on whole cells. In particular, C. albicans were adhered on glass surface, where introduction and removal of reagent solutions were conveniently conducted with a micropipette. Compared to the use of cells suspended in solutions, our treatment of adhered cells also better resembles the antifungal treatment of $C$. albicans cells adhered on tissues in the oral cavity. Importantly, the reduction in reagent volumes from $\mathrm{mL}$ to $\mu \mathrm{L}$ levels will allow users to perform many more replicate assays, while keeping an overall low consumption of reagents and cells. Nevertheless, the downside of the miniaturization is the reduced peptide sample quantity resulting from the LC MS analysis, which could reduce the confidence of the protein identification. Ultimately researchers should select methods based on their purposes. In this case, the miniaturized approach with adhered cells is more effective for high-throughput screenings of cell types or fungicides, while the batch mode with suspended cells is more suitable for a comprehensive profiling of the proteome.

\section{Disclosure}

The paper is a part of M.S. thesis work of S. Fan [34]. Walter L. Siqueira and Ken K.-C. Yeung are Coprincipal Investigators. 


\section{Competing Interests}

The authors declare that there is no conflict of interests.

\section{Acknowledgments}

The work was funded by the University of Western Ontario, the Natural Sciences and Engineering Research Council of Canada (NSERC), and the Canadian Institutes of Health Research (CIHR). Walter L. Siqueira is recipient of CIHR New Investigator Salary Award. The authors acknowledge Ms. Kristina Jurcic for assistance in MALDI MS data acquisition and processing and Ms. Tayebeh Basiri for insightful advices in fungal culturing. Permission to access the University of Western Ontario MALDI Mass Spectrometry Facility is also acknowledged.

\section{References}

[1] P. Sudbery, N. Gow, and J. Berman, "The distinct morphogenic states of Candida albicans," Trends in Microbiology, vol. 12, no. 7, pp. 317-324, 2004.

[2] D. W. Williams, T. Kuriyama, S. Silva, S. Malic, and M. A. O. Lewis, "Candida biofilms and oral candidosis: treatment and prevention," Periodontology 2000, vol. 55, no. 1, pp. 250-265, 2011.

[3] C. J. Seneviratne, L. Jin, and L. P. Samaranayake, "Biofilm lifestyle of Candida: a mini review," Oral Diseases, vol. 14, no. 7, pp. 582-590, 2008.

[4] A. Sanguineti, J. K. Carmichael, and K. Campbell, "Fluconazoleresistant Candida albicans after long-term suppressive therapy," Archives of Internal Medicine, vol. 153, no. 9, pp. 1122-1124, 1993.

[5] D. Vukosavljevic, W. Custodio, A. A. Del Bel Cury, and W. L. Siqueira, "The effect of histatin 5, adsorbed on PMMA and hydroxyapatite, on Candida albicans colonization," Yeast, vol. 29, no. 11, pp. 459-466, 2012.

[6] W. L. Siqueira, W. Zhang, E. J. Helmerhorst, S. P. Gygi, and F. G. Oppenheim, "Identification of protein components in in vivo human acquired enamel pellicle using LC-ESI-MS/MS," Journal of Proteome Research, vol. 6, no. 6, pp. 2152-2160, 2007.

[7] D. Vukosavljevic, W. Custodio, and W. L. Siqueira, "Salivary proteins as predictors and controls for oral health," Journal of Cell Communication and Signaling, vol. 5, no. 4, pp. 271-275, 2011.

[8] J. M. Laudenbach and J. B. Epstein, "Treatment strategies for oropharyngeal candidiasis," Expert Opinion on Pharmacotherapy, vol. 10, no. 9, pp. 1413-1421, 2009.

[9] F. G. Oppenheim, Y. C. Yang, R. D. Diamond, D. Hyslop, G. D. Offner, and R. F. Troxler, "The primary structure and functional characterization of the neutral histidine-rich polypeptide from human parotid secretion," The Journal of Biological Chemistry, vol. 261, no. 3, pp. 1177-1182, 1986.

[10] J. O. Tenovuo, Human Saliva: Clinical Chemistry and Microbiology, CRC Press, 1989.

[11] F. G. Oppenheim, T. Xu, F. M. McMillian et al., "Histatins, a novel family of histidine-rich proteins in human parotid secretion. Isolation, characterization, primary structure, and fungistatic effects on Candida albicans," The Journal of Biological Chemistry, vol. 263, no. 16, pp. 7472-7477, 1988.

[12] E. J. Helmerhorst, P. Breeuwer, W. Van 't Hof et al., "The cellular target of histatin 5 on Candida albicans is the energized mitochondrion," The Journal of Biological Chemistry, vol. 274, no. 11, pp. 7286-7291, 1999.

[13] A. Freiwald and S. Sauer, "Phylogenetic classification and identification of bacteria by mass spectrometry," Nature protocols, vol. 4, no. 5, pp. 732-742, 2009.

[14] G. Marklein, M. Josten, U. Klanke et al., "Matrix-assisted laser desorption ionization-time of flight mass spectrometry for fast and reliable identification of clinical yeast isolates," Journal of Clinical Microbiology, vol. 47, no. 9, pp. 2912-2917, 2009.

[15] S. Sauer and M. Kliem, "Mass spectrometry tools for the classification and identification of bacteria," Nature Reviews Microbiology, vol. 8, no. 1, pp. 74-82, 2010.

[16] C. Liu, S. A. Hofstadler, J. A. Bresson et al., "On-line dual microdialysis with ESI-MS for direct analysis of complex biological samples and microorganism lysates," Analytical Chemistry, vol. 70, no. 9, pp. 1797-1801, 1998.

[17] T. C. Cain, D. M. Lubman, and W. J. Weber, "Differentiation of bacteria using protein profiles from matrix-assisted laser desorption/ionization time-of-flight mass spectrometry," Rapid Communications in Mass Spectrometry, vol. 8, no. 12, pp. 10261030, 1994.

[18] Y.-P. Ho and P. M. Reddy, "Identification of pathogens by mass spectrometry," Clinical Chemistry, vol. 56, no. 4, pp. 525-536, 2010.

[19] P. A. Demirev, N. S. Hagan, M. D. Antoine, J. S. Lin, and A. B. Feldman, "Establishing drug resistance in microorganisms by mass spectrometry," Journal of the American Society for Mass Spectrometry, vol. 24, no. 8, pp. 1194-1201, 2013.

[20] J. P. Anhalt and C. Fenselau, "Identification of bacteria using mass spectrometry," Analytical Chemistry, vol. 47, no. 2, pp. 219225, 1975 .

[21] S. Vaidyanathan, J. J. Rowland, D. B. Kell, and R. Goodacre, "Discrimination of aerobic endospore-forming bacteria via electrospray-ionization mass spectrometry of whole cell suspensions," Analytical Chemistry, vol. 73, no. 17, pp. 4134-4144, 2001.

[22] M. Welker, "Proteomics for routine identification of microorganisms," Proteomics, vol. 11, no. 15, pp. 3143-3153, 2011.

[23] R. D. Holland, J. G. Wilkes, F. Rafii et al., "Rapid identification of intact whole bacteria based on spectral patterns using matrixassisted laser desorption/ionization with time-of- flight mass spectrometry," Rapid Communications in Mass Spectrometry, vol. 10, no. 10, pp. 1227-1232, 1996.

[24] E. B. Moffa, M. C. M. Mussi, Y. Xiao et al., "Histatin 5 inhibits adhesion of $C$. albicans to reconstructed human oral epithelium," Frontiers in Microbiology, vol. 6, article 885, pp. 1-7, 2015.

[25] M. J. Rodríguez-Ortega, N. Norais, G. Bensi et al., "Characterization and identification of vaccine candidate proteins through analysis of the group A Streptococcus surface proteome," Nature Biotechnology, vol. 24, no. 2, pp. 191-197, 2006.

[26] F. Doro, S. Liberatori, M. J. Rodríguez-Ortega et al., "Surfome analysis as a fast track to vaccine discovery: identification of a novel protective antigen for group B Streptococcus hypervirulent strain COH1," Molecular and Cellular Proteomics, vol. 8, no. 7, pp. 1728-1737, 2009.

[27] A. Gil-Bona, C. M. Parra-Giraldo, M. L. Hernáez et al., "Candida albicans cell shaving uncovers new proteins involved in cell wall integrity, yeast to hypha transition, stress response and host-pathogen interaction," Journal of Proteomics, vol. 127, pp. 340-351, 2015. 
[28] M. L. Hernáez, P. Ximénez-Embún, M. Martínez-Gomariz, M. D. Gutiérrez-Blázquez, C. Nombela, and C. Gil, "Identification of Candida albicans exposed surface proteins in vivo by a rapid proteomic approach," Journal of Proteomics, vol. 73, no. 7, pp. 1404-1409, 2010.

[29] V. Vialás, P. Perumal, D. Gutierrez et al., "Cell surface shaving of Candida albicans biofilms, hyphae, and yeast form cells," Proteomics, vol. 12, no. 14, pp. 2331-2339, 2012.

[30] M. R. Insenser, M. L. Hernáez, C. Nombela, M. Molina, G. Molero, and C. Gil, "Gel and gel-free proteomics to identify Saccharomyces cerevisiae cell surface proteins," Journal of Proteomics, vol. 73, no. 6, pp. 1183-1195, 2010.

[31] C. Gyurko, U. Lendenmann, E. J. Helmerhorst, R. F. Troxler, and F. G. Oppenheim, "Killing of Candida albicans by histatin 5: cellular uptake and energy requirement," Antonie van Leeuwenhoek, vol. 79, no. 3-4, pp. 297-309, 2001.

[32] A. Pitarch, M. Sánchez, C. Nombela, and C. Gil, "Sequential fractionation and two-dimensional gel analysis unravels the complexity of the dimorphic fungus Candida albicans cell wall proteome," Molecular \& Cellular Proteomics, vol. 1, no. 12, pp. 967-982, 2002.

[33] T. Komatsu, E. Salih, E. J. Helmerhorst, G. D. Offner, and F. G. Oppenheim, "Influence of histatin 5 on Candida albicans mitochondrial protein expression assessed by quantitative mass spectrometry," Journal of Proteome Research, vol. 10, no. 2, pp. 646-655, 2011.

[34] http://ir.lib.uwo.ca/etd/3243/. 

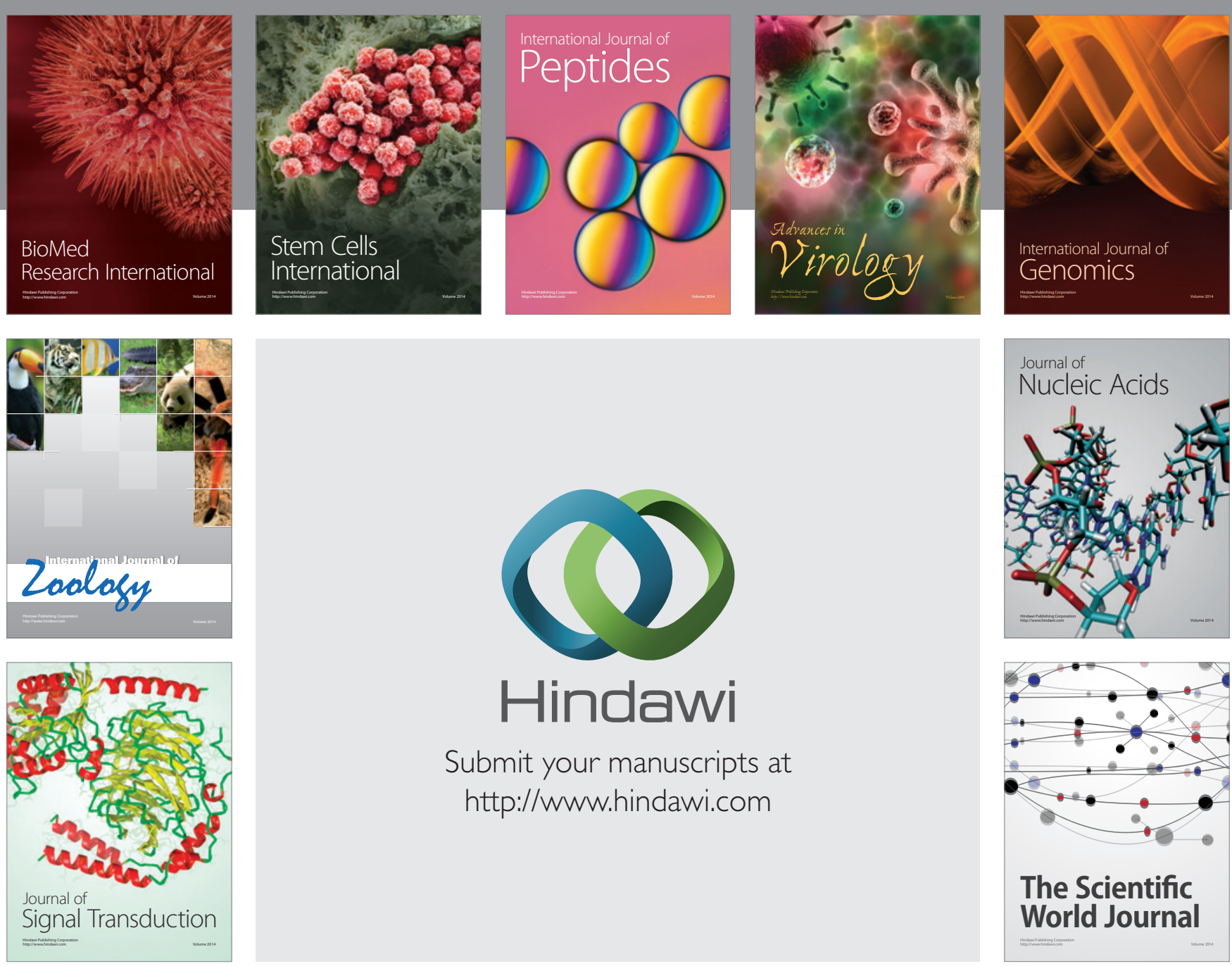

Submit your manuscripts at

http://www.hindawi.com
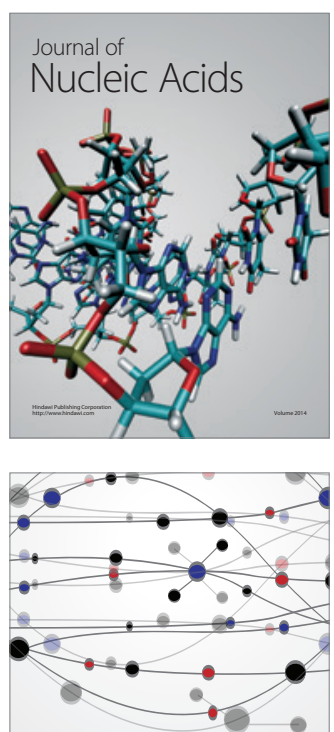

The Scientific World Journal
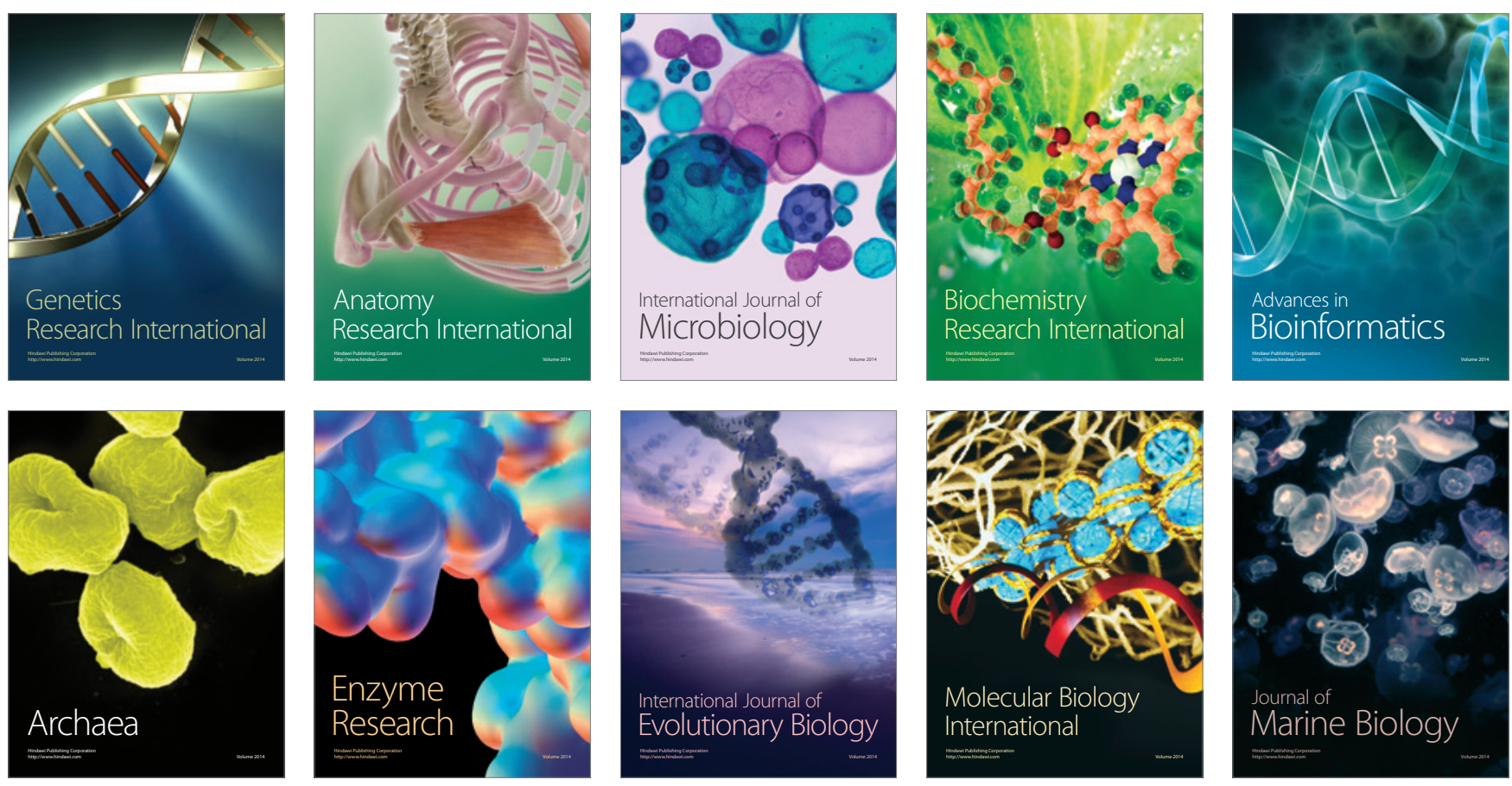